\title{
DISCUSSION
}

\section{A framework for unsaturated soils behaviour}

\author{
D. G. TOI.I. (1990) Géotechnique 40, No. 1, 31-44
}

D. G. Fredlund, H. Rahardjo and J. K. M. Gan, Department of Civil Engineering, University of Saskatchewan

The Paper addressed a most interesting and important problem and attempts to provide a critical state framework for explaining the behaviour of an unsaturated soil. The Author has demonstrated the importance of using two independent stress state variables that represent the total stress and matric suction contributions.

Throughout the Paper, the Author emphasized 'that in unsaturated soils the initial fabric is not destroyed by shearing to large strains'. We have shown that differing fabrics at various degrees of saturation cause variations in the $M_{\mathrm{a}}$ and $\lambda_{\mathrm{a}}$ parameters with respect to degree of saturation. It appears that the specimens were compacted at different water contents (ranging from 17 to $31 \%$ ) and different compactive efforts as shown in Table 2. The initial void ratios and degrees of saturation vary considerably, producing a wide variation in the initial soil fabrics of the specimens.

We question the uniqueness of the relationships presented in the Paper when results from soils with various soil fabrics are combined. A unique rclationship might be anticipated if the initial soil fabrics were destroyed during shear to produce a similar structure at the end of the tests. In the case where the initial soil structure cannot be destroyed at large strains, specimens compacted at the same water content and compactive effort should be used in order to produce socalled 'identical' soil fabric specimens. A unique relationship could then be anticipated from specimens with 'identical' soil fabrics, especially when the fabric is not destroyed during shear. The degrees of saturation of identical specimens could be varied by subjecting the specimens to various matric suctions. The use of identical soil specimens is in keeping with the commonly accepted practices in conventional soil mechanics (Fredlund, 1989). Soils compacted at different water contents or compactive efforts should be considered as different soils, as is recognized by the Author.

Our second comment relates to the shear strength equation as presented in equation (2). The application of equation (2) can also be extended to a non-linear failure envelope as has been presented by Fredlund, Rahardjo \& Gan (1987). A non-linear envelope with varying $\phi^{\prime}$ and $\phi^{\text {b }}$ values would be expected for many compacted soils (Fredlund, 1989) even when the strength envelope is established using data from identical specimens. However, results from non-identical specimens might also be mistakenly interpreted as having non-linear characteristics of the shear strength envelope. Therefore, it is important to use results from identical specimens when establishing shear strength (and volume change) relationships for an unsaturated soil.

Fredlund et al. (1987) expressed the nonlinearity in $\phi^{\text {b }}$ values with respect to matric suction because matric suction can be measured and known at failure. Of course, the soil matric suction bears a relationship to the degree of saturation. However, it is quite difficult, if not impossible, to measure accurately or to predict the degree of saturation of a soil at the point of failure. Generally, it is computed from water content and void ratio measurements.

In summary, we commend the Author for using independent stress state variables to establish the critical state context for unsaturated soil behaviour. However, it may be superior to ensure that initially identical specimens are used in the characterization of shear strength and volume change behaviour of unsaturated soils.

\section{H. D. Schreiner, Imperial College, London}

The Author has introduced an interesting approach by considering the strength and compressibility parameters for applied stress not to be constant. However, the database with which he has supported this hypothesis raises some questions.

First there is the question of the type of test. Blight (1965) showed that $\chi$ is dependent on the type of test. Although Blight does not present numerical data, nor does he present his figure in terms of $S_{r}$, it is evident that the value of $\chi$ at the start of the tests, where the $S_{\mathrm{r}}$ should be the same for all samples varies from 0.15 to 0.5 . Admittedly the critical state approach considers soil at the end of the tests, not at the beginning, but it would be of great interest to know whether or not the same framework could be obtained from, for example, drained tests. 
The second question relates to the attainment of a critical state or constant volume failure condition. Toll states that 'true critical state was not achieved... it will be assumed that end-of-test conditions were close to representing the critical state'. This assumption may be acceptable for his saturated tests, but appears to be doubtful for the unsaturated tests. Working from the graphical data in Toll (1988) Table 6 has been prepared for conditions near the end of the tests. The changes in axial and volumetric strain have been used to calculate $\Delta E_{\mathrm{v}} / \Delta E_{\mathrm{s}}$. This is the term used in the Taylor correction of $M$

$$
q / p^{\prime}=M-\Delta E_{\mathrm{v}} / \Delta E_{\mathrm{s}}
$$

It can be seen from the calculated values of $\Delta E_{\mathrm{v}} / \Delta E_{\mathrm{s}}$ that the rate of dilation at the end of the tests was far from negligible. Applying the Taylor type of correction reduces the values of $M_{\mathrm{a}}$ much closer to the value for saturated samples.

The third question that needs consideration is the extended equation for the specific volume at the critical state

$$
v=T-\lambda_{\mathrm{a}} \ln \left(p-u_{\mathrm{a}}\right)-\lambda_{\mathrm{w}} \ln \left(u_{\mathrm{a}}-u_{\mathrm{w}}\right)
$$

The values given by Toll suggest that the soil becomes more compressible under $\left(p-u_{\mathrm{a}}\right)$ as the degree of saturation decreases. For the saturated critical state model, $\lambda$ gives the slope of both the CSL and the NCL in $v$-log $p^{\prime}$ space. Without any indication to the contrary, it appears reasonable to assume that within the critical state framework for unsaturated soil $\lambda_{\mathrm{a}}$ should represent the slope of the critical state surface with respect to $\left(p-u_{\mathrm{a}}\right)$ as well as the slope of the normally consolidated surface with respect to $\left(p-u_{\mathrm{a}}\right)$.

Figure 6 shows that $\lambda_{\mathrm{a}}$ increases as $S_{\mathrm{r}}$ decreases. I find it difficult to accept that a soil will become more compressible under an increasing applied load and constant suction as the $S_{\text {r }}$ decreases. The reverse certainly appears to be true for double oedometer data where the unsaturated (or natural moisture content) sample is much stiffer than the soaked sample.

\section{Author's reply}

Fredlund, Rahardjo and Gan suggest that by taking 'identical' specimens (compacted at the same water content and using the same compactive effort) and varying the degree of saturation after compaction by changing the matric suction, the values of $M_{\mathrm{a}}$ and $\lambda_{\mathrm{a}}$ for that condition would be unique, i.e. independent of the degree of saturation. It is true that much of the variation in these parameters is due to differences in initial fabric, as is emphasized in the Paper, and it is not possible to separate the effects of degree of saturation per se and of fabric from the data presented. Nevertheless, even for identical samples, $M_{\mathrm{a}}$ and $\lambda_{\mathrm{a}}$ would not be unique. For samples at low suction (high degree of saturation) the 'packet' fabric would be more easily broken down by

\begin{tabular}{|c|c|c|c|c|c|c|c|}
\hline Test & $E_{\mathrm{a} 2}$ & $E_{\mathrm{a} 1}$ & $E_{\mathrm{v} 2}$ & $E_{\mathrm{v} 1}$ & $\Delta E_{\mathrm{v}} / \Delta E_{\mathrm{s}}$ & $M_{*}$ & $M_{\mathrm{a} \text { corr }}$ \\
\hline MGU 1 & 5 & 4 & $2 \cdot 4$ & $2 \cdot 0$ & 0.46 & 1.94 & $1 \cdot 48$ \\
\hline MGU 2 & 8 & 7 & $1 \cdot 4$ & $1 \cdot 2$ & 0.21 & 1.67 & 1.46 \\
\hline MGU 3 & 8 & 7 & $3 \cdot 3$ & $2 \cdot 9$ & 0.46 & 1.89 & 1.43 \\
\hline MGU 4 & 4 & 3 & 1.0 & 0.75 & 0.27 & 1.86 & 1.59 \\
\hline MGU 5 & 5 & 4 & $2 \cdot 8$ & $2 \cdot 0$ & 1.09 & 1.98 & 0.89 \\
\hline MGU 6 & 7 & 6 & 3.8 & $3 \cdot 0$ & 1.09 & 1.97 & 0.88 \\
\hline MGU 7 & 5 & 4 & $2 \cdot 8$ & $2 \cdot 2$ & 0.75 & 2.01 & $1 \cdot 26$ \\
\hline MGU 8 & 5 & 4 & $4 \cdot 3$ & $3 \cdot 4$ & $1 \cdot 23$ & $2 \cdot 00$ & 0.77 \\
\hline MGU 9 & 5 & 4 & $5 \cdot 5$ & $4 \cdot 8$ & 0.91 & 1.98 & 1.07 \\
\hline MGU 10 & 9 & 8 & $1 \cdot 0$ & 0.8 & 0.21 & $1 \cdot 70$ & 1.49 \\
\hline MGU 11 & 9 & 8 & 1.0 & 0.9 & $0 \cdot 10$ & $1 \cdot 71$ & 1.61 \\
\hline MGU 12 & 5 & 4 & $5 \cdot 0$ & $4 \cdot 2$ & 1.09 & 1.75 & 0.66 \\
\hline MGU 13 & 3 & 2 & 3.9 & $2 \cdot 3$ & $4 \cdot 5$ & 1.97 & $?$ \\
\hline MGU 14 & 8 & 7 & $3 \cdot 3$ & $2 \cdot 8$ & $0 \cdot 60$ & $1 \cdot 70$ & $1 \cdot 10$ \\
\hline MGU 15 & 10 & 9 & $1 \cdot 1$ & $1 \cdot 0$ & $0 \cdot 10$ & 1.62 & 1.52 \\
\hline MGU 16 & 8 & 7 & $0-3$ & $0-3$ & 0 & 1.54 & 1.54 \\
\hline MGU 17 & 11 & 10 & 3.8 & $3 \cdot 5$ & 0.33 & 1.58 & 1.25 \\
\hline MGU 18 & 9 & 8 & $5 \cdot 0$ & $4 \cdot 5$ & 0.60 & 1.68 & 1.08 \\
\hline MGU 19 & 10 & 9 & $7 \cdot 7$ & $7 \cdot 3$ & 0.46 & 1.51 & 1.05 \\
\hline MGU 20 & 8 & 7 & $7 \cdot 2$ & $6 \cdot 4$ & 1.09 & 1.73 & 0.64 \\
\hline MGU 21 & 8 & 7 & 0.5 & 0.4 & $0 \cdot 10$ & 1.67 & 1.57 \\
\hline MGU 22 & 8 & 7 & $7 \cdot 3$ & 6.8 & 0.60 & 1.75 & $1 \cdot 15$ \\
\hline MGU 23 & 8 & 7 & 5.7 & $5 \cdot 0$ & 0.91 & 1.61 & 0.70 \\
\hline
\end{tabular}

Table 6. Calculation of corrected $M_{n}$ value 
shearing or compression, than at high suctions (low degree of saturation), when the packets would be much stronger and would resist breakdown. Therefore, even if the initial fabrics were identical, the final fabrics would be different and this would result in variation in the values of $M_{\mathrm{a}}$ and $\lambda_{\mathrm{a}}$.

To investigate the effects of degree of saturation per se it would certainly be interesting to perform tests on identical samples. Ideally one would perform tests on samples reconstituted from a slurry, following a known stress history, and also following a known drying/wetting history. It may be that for initially saturated reconstituted soils where the fabric would be considerably simpler than in compacted soils, unique values of $M_{\mathrm{a}}$ and $\lambda_{\mathrm{a}}$ would be observed.

Schreiner rightly points out that the rate of change of volumetric strain with shear strain $\delta \varepsilon_{\mathrm{v}} / \delta \varepsilon_{\mathrm{s}}$ is not insignificant even at the end of the tests. However, attempting to use the Taylor correction of $M$ is flawed in that this assumes that the work done against dilation is done only against the total stress component $\left(p-u_{\mathrm{a}}\right)$. Of course, in an unsaturated soil, work is being done against the two stress components $\left(p-u_{\mathrm{a}}\right)$ and $\left(u_{\mathrm{a}}-u_{\mathrm{w}}\right)$. The expression would therefore become

$$
\frac{q}{\left(p-u_{\mathrm{a}}\right)}+\frac{q}{\left(u_{\mathrm{a}}-u_{\mathrm{w}}\right)}=M_{\mathrm{a}}+M_{\mathrm{w}}-\frac{\delta \varepsilon_{\mathrm{v}}}{\delta \varepsilon_{\mathrm{s}}}
$$

It is therefore necessary to 'share' the correction between $M_{\mathrm{a}}$ and $M_{\mathrm{w}}$, and it is not clear to me on what basis this should be done. Applying the correction only to $M_{\mathrm{a}}$ results in rather low and unrealistic corrected values of $M_{\mathrm{a}}$, as given by Schreiner.

The difficulty of distinguishing between degree of saturation per se and fabric (which in a compacted soil may be related to the degree of saturation) is again illustrated by Schreiner's comments that one would expect the value of $\lambda_{\mathrm{a}}$ to decrease with reducing degree of saturation. As is explained in the Paper, the increase in $\lambda_{\mathrm{a}}$ is due to a more open fabric in the samples compacted at lower degrees of saturation.

\section{REFERENCES}

Blight G. E. (1965). A study of effective stresses for volume change. Moisture equilibria and moisture changes in soils beneath covered areas. Butterworths, Australia.

Fredlund, D. G. (1989). The character of the shear strength envelope for unsaturated soils. De Mello Volume, pp. 142-149.

Fredlund, D. G., Rahardjo, H. \& Gan, J. K. M. (1987). Nonlinearity of strength envelope for unsaturated soils. Proc. 6th Int. Conf. Expansive Soils, New Delhi, pp. 49-54. Rotterdam: Balkema.

Toll, D. G. (1988). The behaviour of unsaturated compacted naturally occurring gravel. $\mathrm{PhD}$ thesis, University of London. 